\title{
Uses of platelet-rich plasma in dentistry: What's the confusion about?
}

Sir,

The ultimate goal of any oral therapeutic procedure is to protect and maintain the patient's natural dentition for his or her lifetime. A recent innovation in dentistry is the preparation and use of platelet-rich plasma (PRP), a concentrated suspension of the growth factors found in platelets. These growth factors are involved in wound healing and are postulated as promoters of tissue regeneration. PRP is a new application of tissue engineering, biotechnology and a rapidly developing area for clinicians and researchers today. ${ }^{[1]}$ In real terms, PRP is just a volume of autologous plasma that has a platelet concentration above baseline. It is a storage vehicle for growth factors, especially which primarily influence bone regeneration. Because of its newness, there is a potential for misunderstanding, misuse, and application of what the practitioner may incorrectly think is PRP. Moreover, since this is an autologous preparation, any concerns regarding disease transmission and immunogenic reactions regarding allograftic and xenograftic preparations can be eliminated. ${ }^{[2]}$

In implant dentistry, the most important application of PRP would definitely be to accelerate autogenous grafts used for site preparations, sinus lifts, osseointegration, ridge augmentations, etc. However, till date, no positive clinical benefits have been documented in the literature citing these phenomena, with the use of PRP with non-vital bone substitutes. ${ }^{[3]}$ Thus, the whole target of PRP remains applicable to basic osteoprogenitor and stem cells. Additionally, well-enhanced bone regeneration can be anticipated when PRP is used with mixtures of autogenous bone with recombinant human growth factors such as recombinant BMP. However, early results are very promising when PRP is placed in the preparation site of a dental implant specifically in the maxilla, in areas of previous failures, in the osteoporotic woman, etc. ${ }^{[4,5]}$

Marx and coworkers performed the first and most compelling study available on the use of PRP in combination with bone grafts. They propounded that grafts combined with PRP showed twice the graft maturity index calculated from a subjective radiographic assessment over the positive control sites, i.e., cancellous cellular marrow grafts. ${ }^{[6]}$ In general, healing proceeds by repair and regeneration after any surgical procedure; however, it does not fully restore the architecture or function of the affected unit. After surgery, platelets begin to form a stable blood clot, releasing a variety of growth factors that induce and support healing and tissue formation. Administration of these growth factors may be combined with tissue regeneration techniques in the repair of intrabony defects, furcations, and cyst cavities. A recently developed procedure can be used to create PRP that has been demonstrated to induce healing and regeneration of tissues, including those in the surgical area. Although the growth factors and the mechanisms involved are still poorly understood, the ease of applying PRP in the dental clinic and its beneficial outcomes, including reduction of bleeding and rapid healing, holds promise for further procedures. This letter is an attempt to grab the attention of researchers to this novel materialistic aspect of dentistry and authors look forward for some new-fangled studies using wider parameters to authenticate and establish certain concrete guidelines in this perspective.

\section{Deepti Srivastava, Sukant Sahoo, Suraj Suvarna, Rakesh Mittal}

Department of Prosthodontics, Shree Bankey Bihari Dental College and Research Centre, Ghaziabad, Uttar Pradesh, India, ${ }^{1}$ Department of Pediatric Dentistry, NIMS Dental College, Jaipur, Rajasthan, India

Address for the Correspondence:

Dr. Sukant Sahoo, Department of Prosthodontics, Shree Bankey Bihari Dental College and Research Centre, Masuri, Ghaziabad - 201302, India. E-mail: princekumar@its.edu.in

\section{REFERENCES}

1. Zechner W, Tangl S, Tepper G, Fürst G, Bernhart T, Haas R, et al. Influence of PRP on osseous healing of dental implants. Int $\mathrm{J}$ Oral 
Maxillofac Implants 2003;18:15-22.

2. Froum SJ, Wallace SS, Tarnow DP, Cho SC. Effect of Platelet-Rich Plasma on Bone Growth and Osseo integration in Human Maxillary Sinus Grafts: Three Bilateral Case Reports. Int J Periodontics Restorative Dent 2002;22:45-53.

3. Shanaman R, Filstein MR, Danesh-Meyer MJ. Localized Ridge Augmentation Using GBR and Platelet-Rich Plasma: Case Reports. Int J Periodontics Restorative Dent 2001;21:345-55.

4. Sánchez AR, Sheridan PJ, Kupp LI. Is PRP a perfect enhancement factor? A current review. Int J Oral Maxillofac Implants 2003;18:93-103.

5. Anitua E. Plasma Rich in Growth Factors: Preliminary Results of Use in the Preparation of Future Sites for Implants. Int J Oral Maxillofac Implants 1999:14:529-35.

6. Trisi P, Rebaudi A, Calvari F, Lazzara RJ. Sinus graft with Biogran,
Autogenous bone, and PRP. A report of 3 cases with histology and micro CT. Int J Periodontics Restorative Dent 2006;26:113-25.

\begin{tabular}{|l|l|}
\hline Access this article online & Website: \\
\hline Quick Response Code: & ww.ijmedph.org \\
\hline & \\
\hline
\end{tabular}

